\title{
Development of a Cost Effective Beverage and Food-Serving Robot for Hygienically Outcomes and Human Comfort
}

\author{
Ramandeep Singh ${ }^{1}$, Mukul Sain ${ }^{2}$, Balveer Singh ${ }^{3}$, \\ Harpreet Singh Nagi ${ }^{1}$ and Niraj Bala ${ }^{1}$
}

${ }^{1}$ Department of Mechanical Engineering, ${ }^{2}$ Department of Agricultural Engineering, ${ }^{3}$ Department of Computer Science \& Engineering, Baba Banda Singh Bahadur Engineering College, Fatehgarh Sahib, 140407, India

*Corresponding author

\section{A B S T R A C T}

\section{Keywords}

Serving robots, food and beverages sector, Bluetooth Controlled Robot, ATmega328

\section{Article Info}

Accepted: 05 April 2020 Available Online: 10 May 2020
The robotics and automation in its execution have worked tremendously generating welldefined processes in the food and beverages sector, maintaining good hygiene in hospitals for serving the patients and old ages. It prevents the human touch resulting in proper hygiene. It also decreases labor dependence and increases economic benefits. Based on this fact, a serving robot was developed for food, medicines and other goods, especially beverages from one place to another. Developed robot was a self-guided programmed machine, a programming based robot where all the commands were managed by the main controller ATmega328. In this process, IR sensors, ultrasonic sensors, and encoders transmit input signals to the main controller and output signals were received by the liquid pump, led, gear motors to perform different functions. All steps of the robot were been displayed on the LED (Light Emitting Diode) screen, which was connected to the perfect position to make it capable of serving more effectively and attractively. The existing robot can also be developed to make it multipurpose and can be used at large scale by increasing the size and capacity.

\section{Introduction}

In present era, the population is increasing rapidly, and management is becoming a very hard task. The number of assistances is required to manage different operations in food and beverages sector, Hospitals, etc. The current issue is about contamination with human touch in the fields of hospitals and food \& beverage sectors. Generally, there is lack of hygiene in industries because of human touch and crowd around. These two sectors are directly connected with human life and disturbance in these fields can cause unbearable consequences. Transportation is becoming more challenging as per the 
increased population demand. To overcome this problem, fast \& smooth automation is required with the aim of getting good results and flexible outcomes (Wallin, 1997, Nayik et al., 2015).

A robot is a machine, particularly programmable by a computer, used for completing an arrangement of activities automatically. Robotics gives tremendous outputs in various sectors and makes the tasks easy (Hurd et al., 2005). Also, the robots are more precise and accurate (Narendra et al., 2010). Robots can be guided by using different computer based programmes and sensors, and are built to provide comfort in daily lifestyle. They can be of various types viz.Stationary Robots, wheeled Robots, swimming robots, mine Robot, flying robots, modular robots, soccer robots, etc.

In this paper, a smart service robot was developed which implements its motions with the help of three moving wheels, in which two wheels are connected with gear motors for smooth and best performance while taking turns and to complete the task. These type of smart labours are capable to improve the quality of serving in industries, hospitals, etc. with the consideration of good hygiene and accurate working.

With the futuristic approach, there is great need of standardize risk hazards caused because of human interaction (Khan et al., 2014). COVID-19, which is the biggest issue that the whole world is facing at present time because of which life is almost stopped. Using such robots, these types of communicable diseases and other viruses, bacteria, pathogens can be stopped from spreading, as it prevents human touch. Also, The operations carried out by the modern robots have greatly decreased the accidents to the workers because of very less physical involvement of human.
The main objectives of this study include that to develop an IoT based serving robot. And also testing of the developed robot.

\section{Materials and Methods}

In the development process, IR sensors, ultrasonic sensors, and encoders were used to transmit input signals to the main controller and output signals were received by the water pump, led(Light Emitting Diode), gear motors to perform different functions as per requirements.

For the fabrication of robot, different electronics, electrical and mechanical equipment were used to make it innovative as per today's need. It was an IoT (Internet of Things) based product in which different types of equipment were connected to communicate with each other based on programming, which avoid human errors and gives best outcomes based on computer-aided machines to control the devices and to complete different tasks within the expectations and demands (Chivarov et al., 2019). By using the mobile-based app, the robot can be controlled which is further controlled by Bluetooth module up to $10 \mathrm{~m}$ distances. The ATmega328 controls all the commands.

\section{Bluetooth}

Bluetooth was used as a remote-control application, as shown in Fig 1, which was found suitable for a sufficient range communication system. These modules were used to control the battery-powered systems and the data was sent in the packets. The range in which this has been controlled is upto $10 \mathrm{~m}$. This module can be operated in the free band range of $2.400 \mathrm{GHz}$ to $2.485 \mathrm{GHz}$.

\section{Encoder}

An encoder is a gadget, circuit, transducer, 
programming system, which was used for the calculation of angular frequency and angular rotation. In this system, the no. of rotation cycles of the wheel for the exact motion of the robot and to precise the steps of rotation was calculated. The encoder can calculate the pulse for the perfect motion of the robot, or in other words, to get the fixed and exact distance to travel as be shown in Fig. 2. IR(Infrared) sensor was used to calculate the number of rotations done by the wheel with the help of zebra strip, in which two colors were present namely black and white and IR sensor does not detect the black color, therefore we got the distance estimation in terms of pulse modulation which was further used to manage the travel path.

\section{IR sensor}

It is a type of sensor which consists of two LEDs (black \& white) in which, white emits the infrared light $\&$ black receives the signal after striking on any object as shown in Fig. 3. This sensor was used to deliver beverages by attaching a pump with Arduino, controlled with the help of this sensor and also used to control the roller to throw disposal glasses \& waste material inside dustbin attached at the end of the roller. Fig. 4 shows the picture of IR sensor with the effective distance range of $2 \mathrm{~cm}$ to $10 \mathrm{~cm}$. A fixed amount of liquid can be delivered based on programming and the flow of the liquid stops when the sensor gets stopped. In other words, when glass gets lifted from the sensor it will immediately stop working, and a fixed amount of liquid will be delivered with the help of programmed timer.

\section{Ultrasonic sensor}

The ultrasonic works on the sound signals to measure distance by using pulse modulation formulation, in which sound signals are transmitted with the frequency more than the human audible range $(>20 \mathrm{KHz})$. It was used to detect obstacles in the way of approaching the destination for serving beverages \& food as shown in Fig. 5.

\section{Relay}

It is a type of switch, which is used to manage the overall requirement of voltage to operate the equipment, by providing extra battery source. There are three pins in relay module, namely VCC (voltage at the common collector), GND (Ground) and signal pin as shown in fig. 6. It works on the electromagnetic effect, in which mutual induction took place when get a signal from the microcontroller. It was used to switch on $\&$ off and to manage the voltage for pump and Led light.

\section{Microcontroller}

Microcontroller is used to control input \& output signals, based on programming. In other words, microcontroller works like a central processing unit in which microprocessor plays the role of managing the data. It consists of different electronics parts like a voltage regulator, resistors, pins, system on the chip, etc. In this robot, Arduino Uno (ATmega328) was used to control the robot as shown in Fig. 7.

\section{Led display}

The Led display was used to put message on the screen, and it is also useful during nighttime to recognize the robot's presence and its eyes also glow to make it more attractive and effective, as shown in Fig 8.

\section{Controlling app}

It is a Bluetooth controlled remote app to control the motion of the robot which was used to give start command and can also be used to adjust the path of the programmed 
robot as shown in fig. 9. This app can control the motion of robots up-to $10 \mathrm{~m}$ distance, which can be very useful in homes, industries, etc. It can also be used to operate the motion of the robot manually.

The outer shell of the robot for fitting all the above-discussed technical items was fabricated using following materials:

\section{Wooden structure}

$5.0 \mathrm{~mm}$ waterproof plywood was used to make the structure of the robot in which three sections were made,

Upper Portion, to installed beverages camper, food tray, medicines and other goods and to place fresh disposal glasses.

Middle Portion, to installed electronics and electrical units with a moving roller attached with dustbin at the lower portion.

Lower Portion, to placed the battery, dustbin and other useful stuffs. Dimensions of robot, Length $(x=43 \mathrm{~cm}, y=125 \mathrm{~cm}, z=50 \mathrm{~cm})$

\section{Metallic head}

To give semi-humanoid look, the head was made up of metallic material, which was placed on the top.

\section{Wheels}

Two wooden wheels were installed, having $5 \mathrm{~cm}$ width $\& 10.8 \mathrm{~cm}$ diameter and one castor.

\section{Glass tray}

A glass tray was fitted to put food items and beverages,etc of thickness $5 \mathrm{~mm}$.

\section{Dustbin}

To make this robot eco-friendly,a dustbin was attached at the end of the roller in the lower portion.

\section{Glass camper}

To store beverages, a glass camper or storage container was placed on the top portion with the storage of $3 \mathrm{~L}$.

\section{Working procedure and concept}

The working of this robot was based on programming and other essential equipment. The main controller was attached with input and output equipment to fetch and manage the data. This ATmega328 programmed based robot follows the path as shown in fig. 12 .

Also, given details shown in Fig. 10, Fig. 11, and Fig. 12 make the concept easier to understand because of its smooth and hightech working. The processing ofControl Unit isshown in Fig. 10 and Fig.11 defines its processing, in which the robot starts from its initial position and retraced back, after serving the goods and beverages.

Robot required $12 \mathrm{v}$ supply to initiate the process. The developed service robot can serve all types of food items like snacks, lunch, diner, medicines and all types of beverages like water, juice, soft drinks, etc. For beverage serving, there was a beverage storage container in which the liquid which was supposed to serve was filled and the container was further connected with the pump through the pipe.

Flow was managed with the help of sensor which is connected with microcontroller based on programming. The robot was able to serve to the number of persons present on the programmed path.

The process of automation was managed by different sensors to avoid accidents and other errors. The microcontroller was fitted for management of outputs and input actions by sensing and fetching data from sensors and performing the output functions to accomplish 
the task.

It serves beverages on the basis of programming. The robot is programmed to wait if any obstacle comes in the path of motion and then we can make the turning with the help of mobile-based Bluetooth app (acting as a remote).

\section{Results and Discussion}

The developed robot was tested based on different programs and paths. The path coverage timing depends on the number of wheels rotations and chances of obstacles in the path to destination. The Overall efficiency of battery was found good as per number of rounds and repetitions. It was able to work both day and nighttime as led light was displaced on the top and inside robot's eyes. The following outcomes were calculated and checked based on robot's performance as shown in table 1 and table 2 and Fig. 13.

Table.1 Motor RPM, speed of the robot and accuracy based on perfect turings

\begin{tabular}{|c|c|c|c|c|c|c|c|}
\hline $\begin{array}{l}\text { Name of } \\
\text { Equipment }\end{array}$ & $\begin{array}{l}\text { Circumference } \\
\text { of moving } \\
\text { wheel in } \\
\text { centimeters }\end{array}$ & $\begin{array}{c}\text { Motor } \\
\text { Rotation } \\
\text { per } \\
\text { minute } \\
\text { (RPM) }\end{array}$ & $\begin{array}{l}\text { Motor } \\
\text { Rotation } \\
\text { per } \\
\text { second } \\
\text { (RPS) }\end{array}$ & $\begin{array}{c}\text { Time } \\
\text { in } \\
\text { seconds }\end{array}$ & $\begin{array}{l}\text { Distance in } \\
\text { centimeters }\end{array}$ & $\begin{array}{c}\text { Speed in } \\
\text { centimetres } \\
\text { /seconds }\end{array}$ & $\begin{array}{c}\text { Accuracy } \\
\text { based on } \\
\text { perfect } \\
\text { turnings }\end{array}$ \\
\hline $\begin{array}{l}\text { Wheel } \\
\text { (Gear } \\
\text { Motors) }\end{array}$ & $\begin{array}{l}2 \pi r= \\
2 * 3.14 * 5.4 \\
=33.912\end{array}$ & 15 & 0.25 & 60 & 508.68 & 8.478 & Best \\
\hline $\begin{array}{l}\text { Wheel } \\
\text { (Gear } \\
\text { Motors) }\end{array}$ & $\begin{array}{l}2 \pi \mathrm{r}= \\
2 * 3.14 * 5.4 \\
=33.912\end{array}$ & 20 & 0.33 & 45 & 508.68 & 11.304 & Better \\
\hline $\begin{array}{l}\text { Wheel } \\
\text { (Gear } \\
\text { Motors) }\end{array}$ & $\begin{array}{l}2 \pi r= \\
2 * 3.14 * 5.4 \\
=33.912\end{array}$ & 25 & 0.41 & 36 & 508.68 & 14.13 & v. Good \\
\hline $\begin{array}{l}\text { Wheel } \\
\text { (Gear } \\
\text { Motors) }\end{array}$ & $\begin{array}{l}2 \pi r= \\
2 * 3.14 * 5.4 \\
=33.912\end{array}$ & 30 & 0.5 & 30 & 508.68 & 16.956 & Good \\
\hline
\end{tabular}

Table.2 Table for dispensed liquid and number of glasses filled

\begin{tabular}{|l|c|c|c|c|c|}
\hline $\begin{array}{l}\text { Beverage } \\
\text { storage } \\
\text { capacity in } \mathbf{~ m l}\end{array}$ & $\begin{array}{c}\text { Beverages flow } \\
\text { rate in ml/sec }\end{array}$ & $\begin{array}{c}\text { Sensor } \\
\text { Timing in } \\
\text { seconds }\end{array}$ & $\begin{array}{c}\text { Beverage } \\
\text { dispensed in ml }\end{array}$ & $\begin{array}{c}\text { No. of glasses } \\
\text { filled }\end{array}$ & $\begin{array}{c}\text { Status of } \\
\text { glasses with } \\
\mathbf{2 5 0 m l} \\
\text { capacity }\end{array}$ \\
\hline $\mathbf{3 0 0 0}$ & $33.3 \mathrm{ml} / \mathrm{sec}$ & $3.76 \mathrm{sec}$ & 125.20 & 24 & Half \\
\hline $\mathbf{3 0 0 0}$ & $33.3 \mathrm{ml} / \mathrm{sec}$ & $5.62 \mathrm{sec}$ & 187.14 & 16 & $3 / 4$ of full \\
\hline $\mathbf{3 0 0 0}$ & $33.3 \mathrm{ml} / \mathrm{sec}$ & $7.5 \mathrm{sec}$ & 249.75 & 12 & full \\
\hline
\end{tabular}




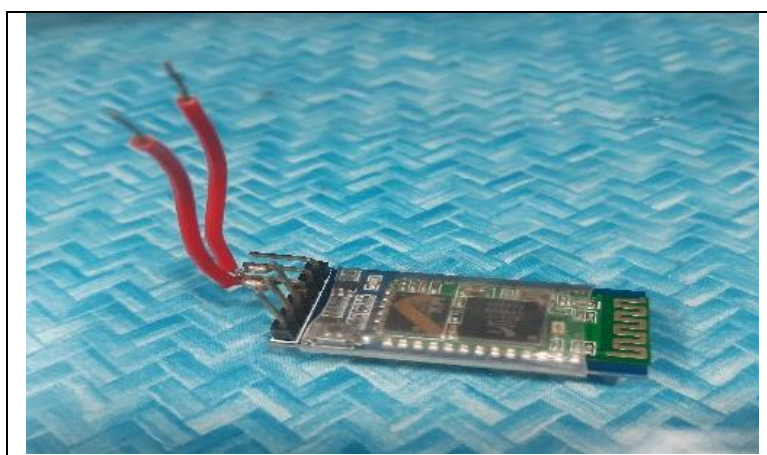

Fig.1 HC-05 Bluetooth Module
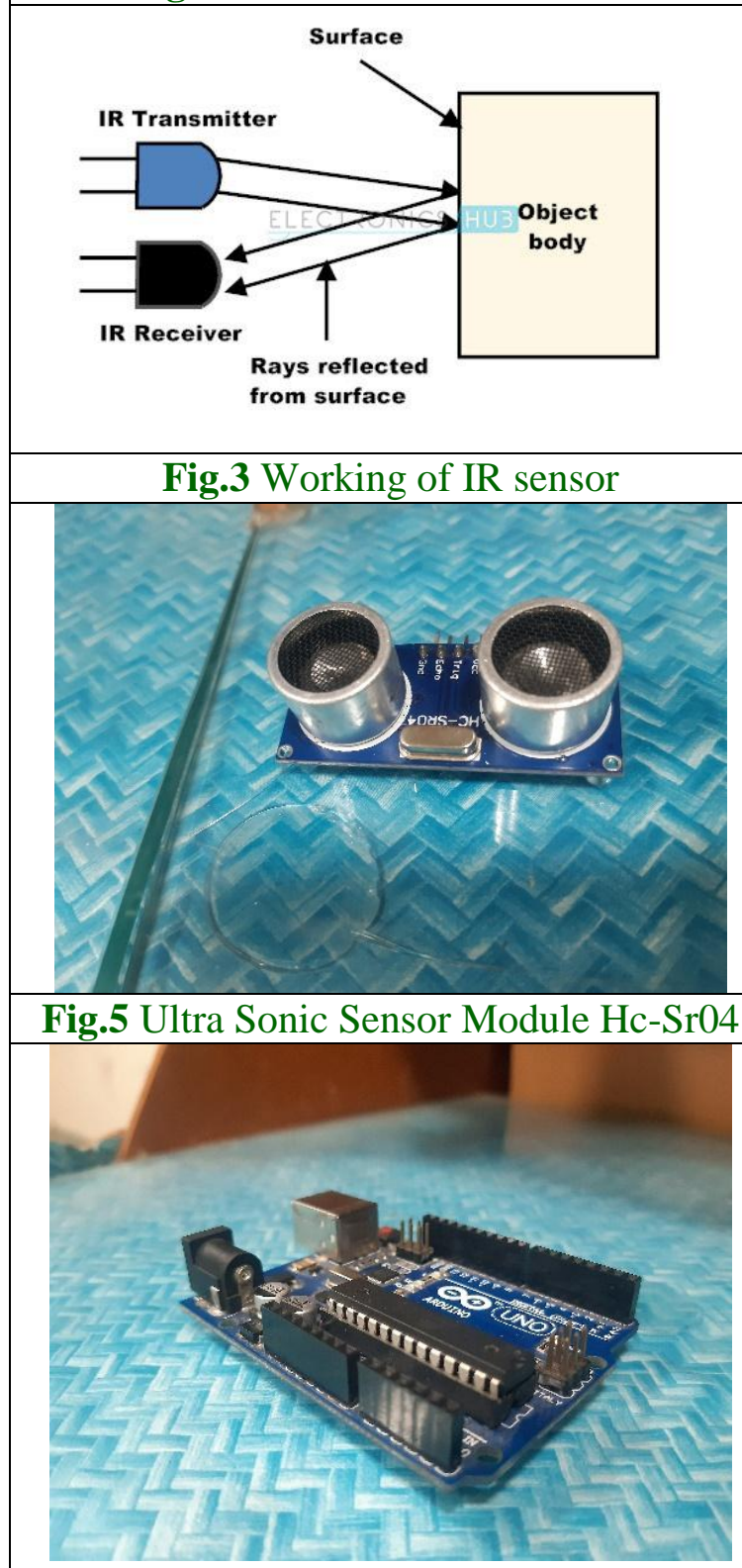

Fig.7 Arduino Uno ATmega328
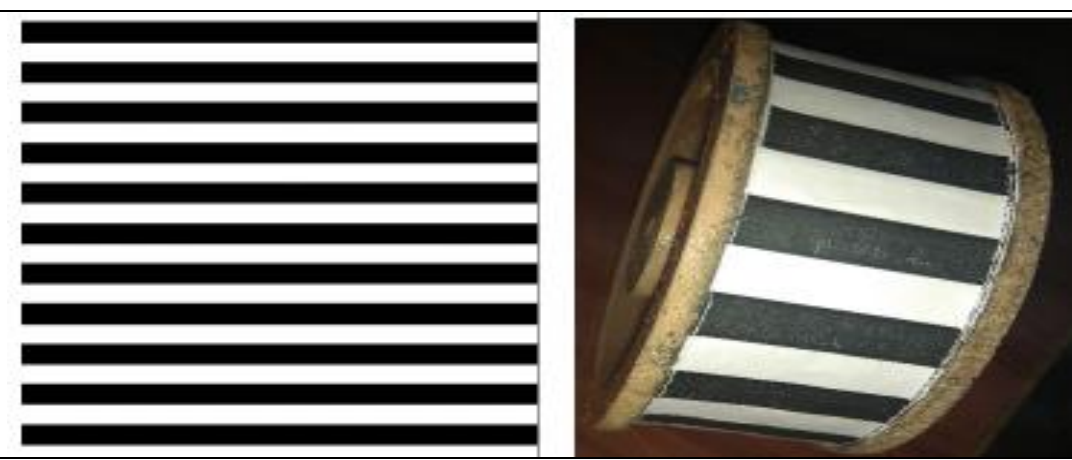

Fig.2 Encoder for measuring angular rotation

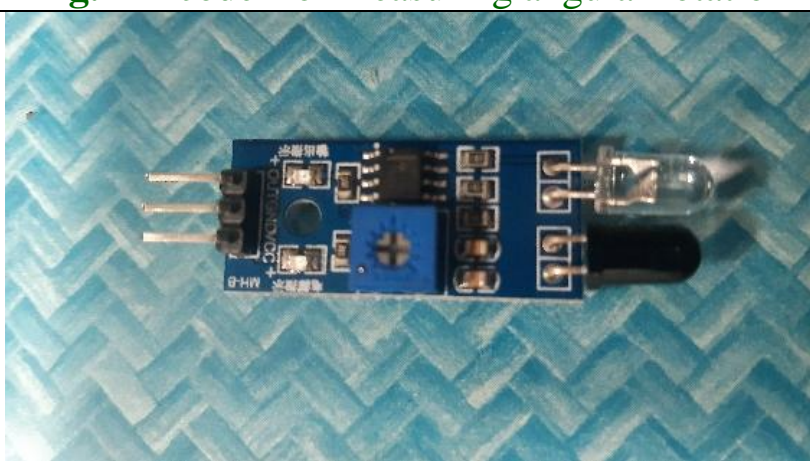

Fig.4 IR sensor

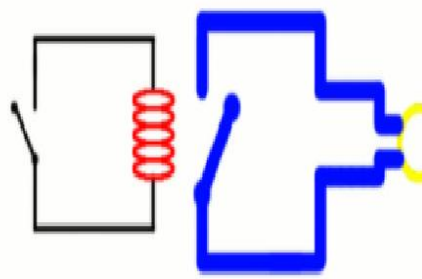

Input circuit Output circuit

(low-current) (high-current)

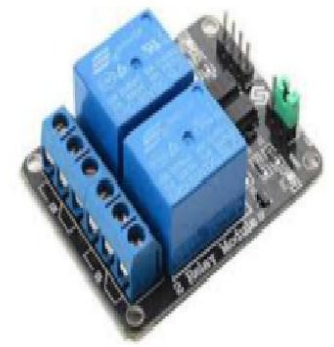

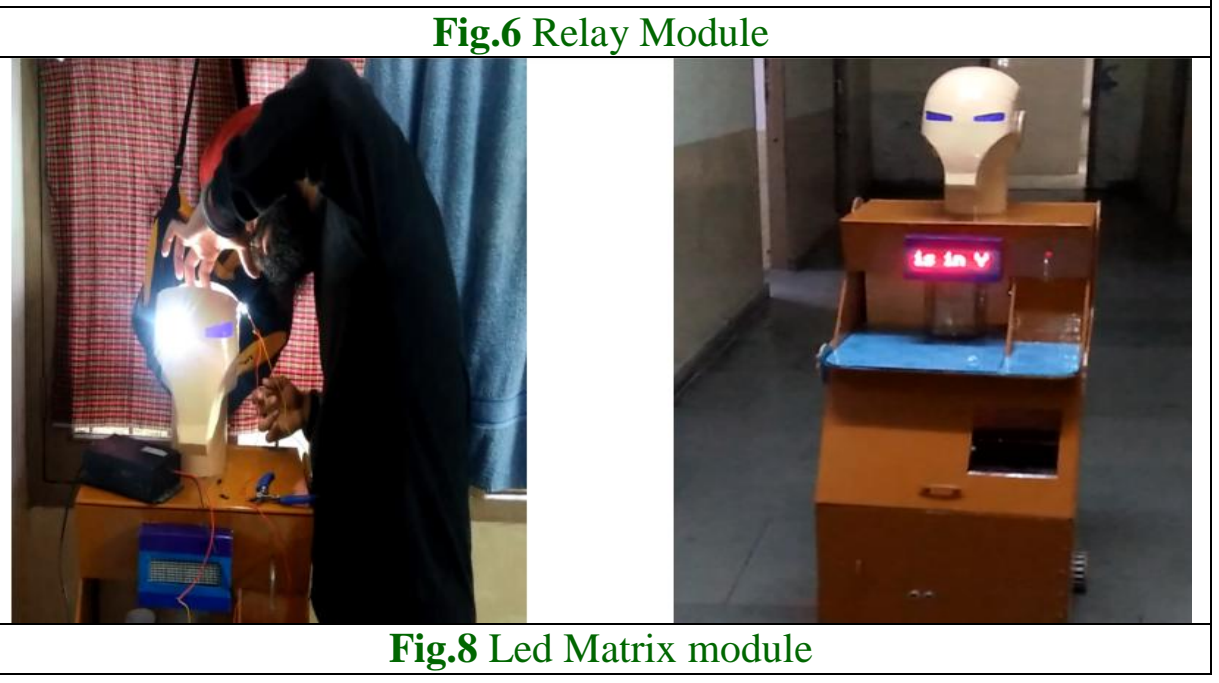




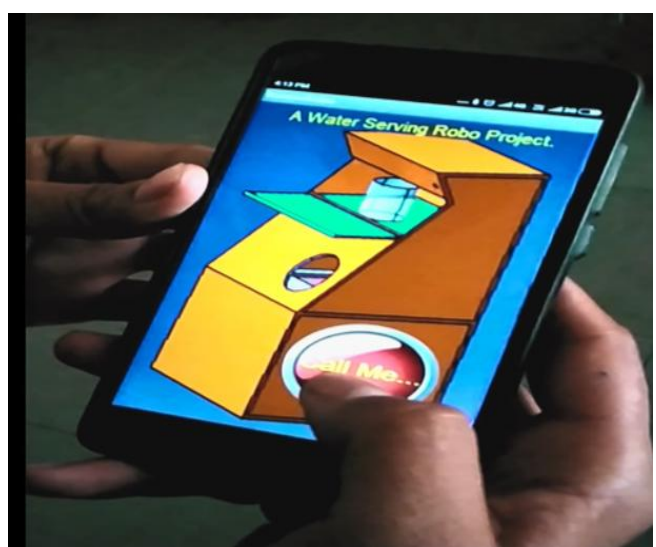

Fig.9 The Bluetooth controlled Remote app

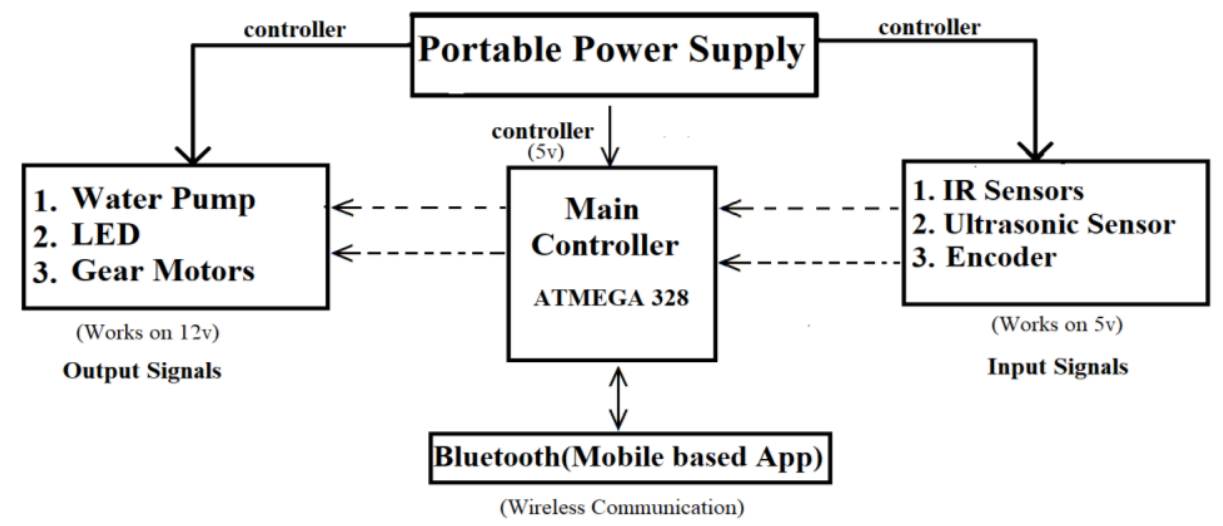

Fig.10 Block Diagram of Control Unit

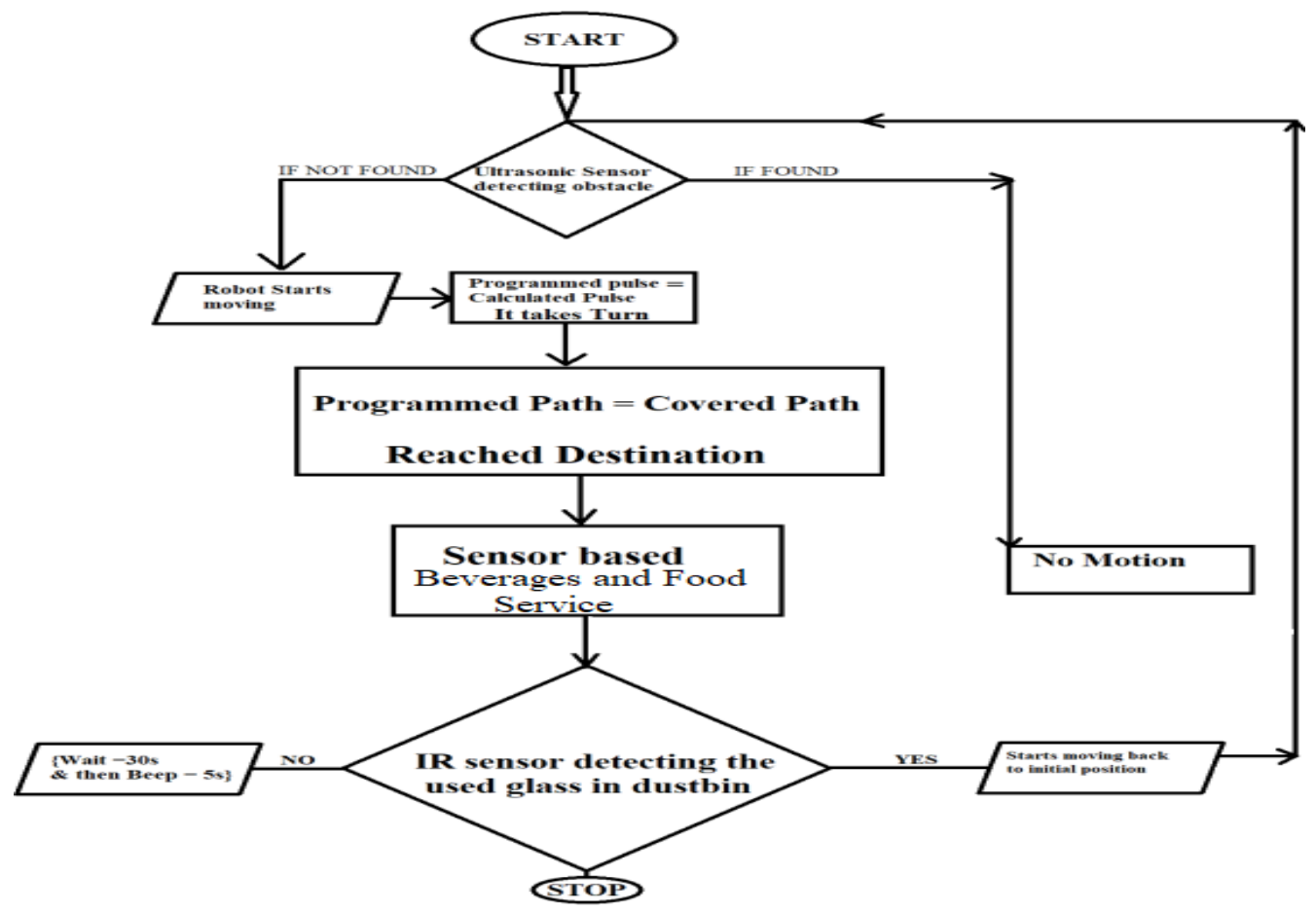

Fig.11 Flow Chart of Robotic Programming 


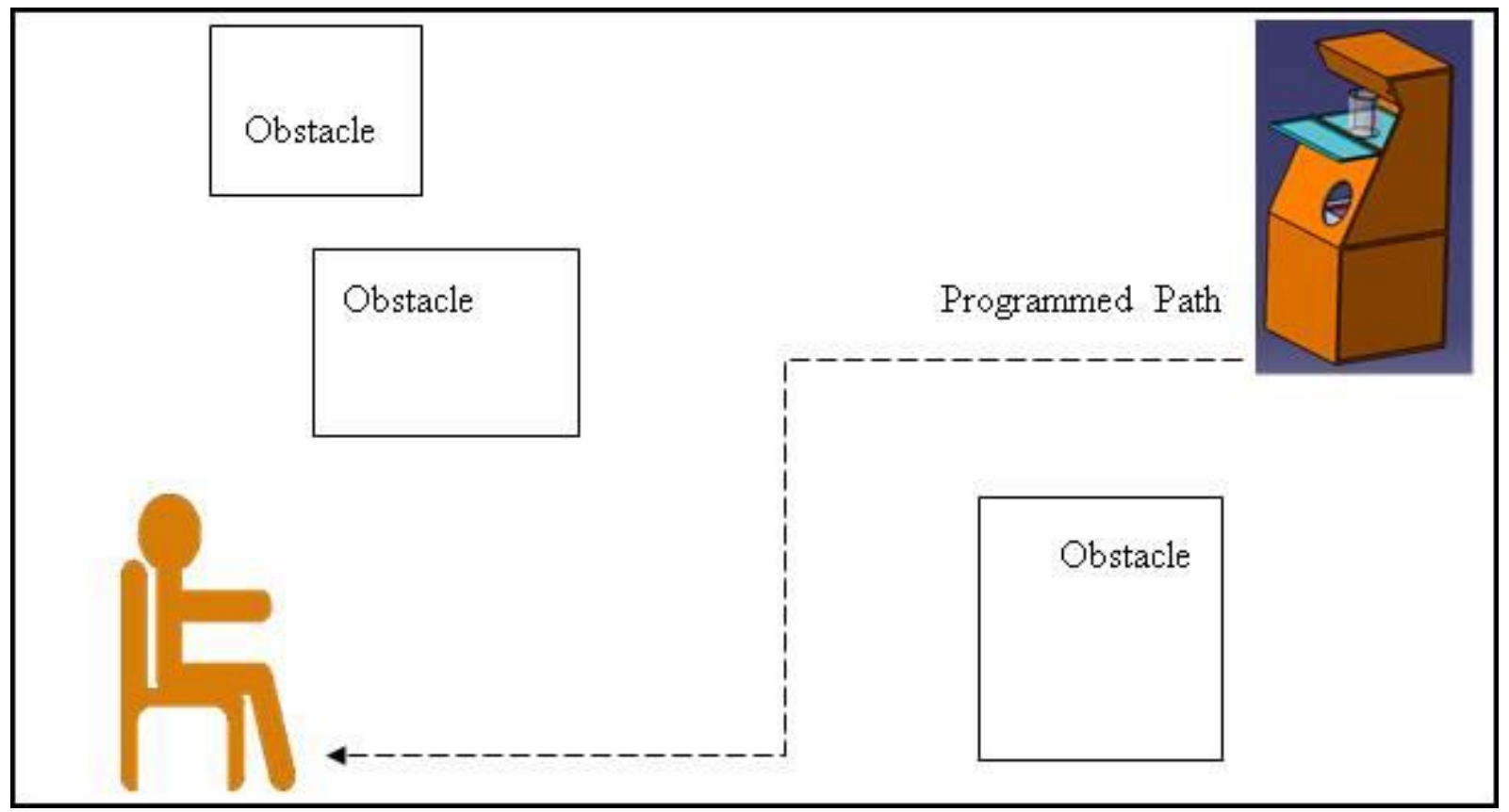

Fig.12 Path map of Serving Robot

Rotation per second (RPS) v/s Speed

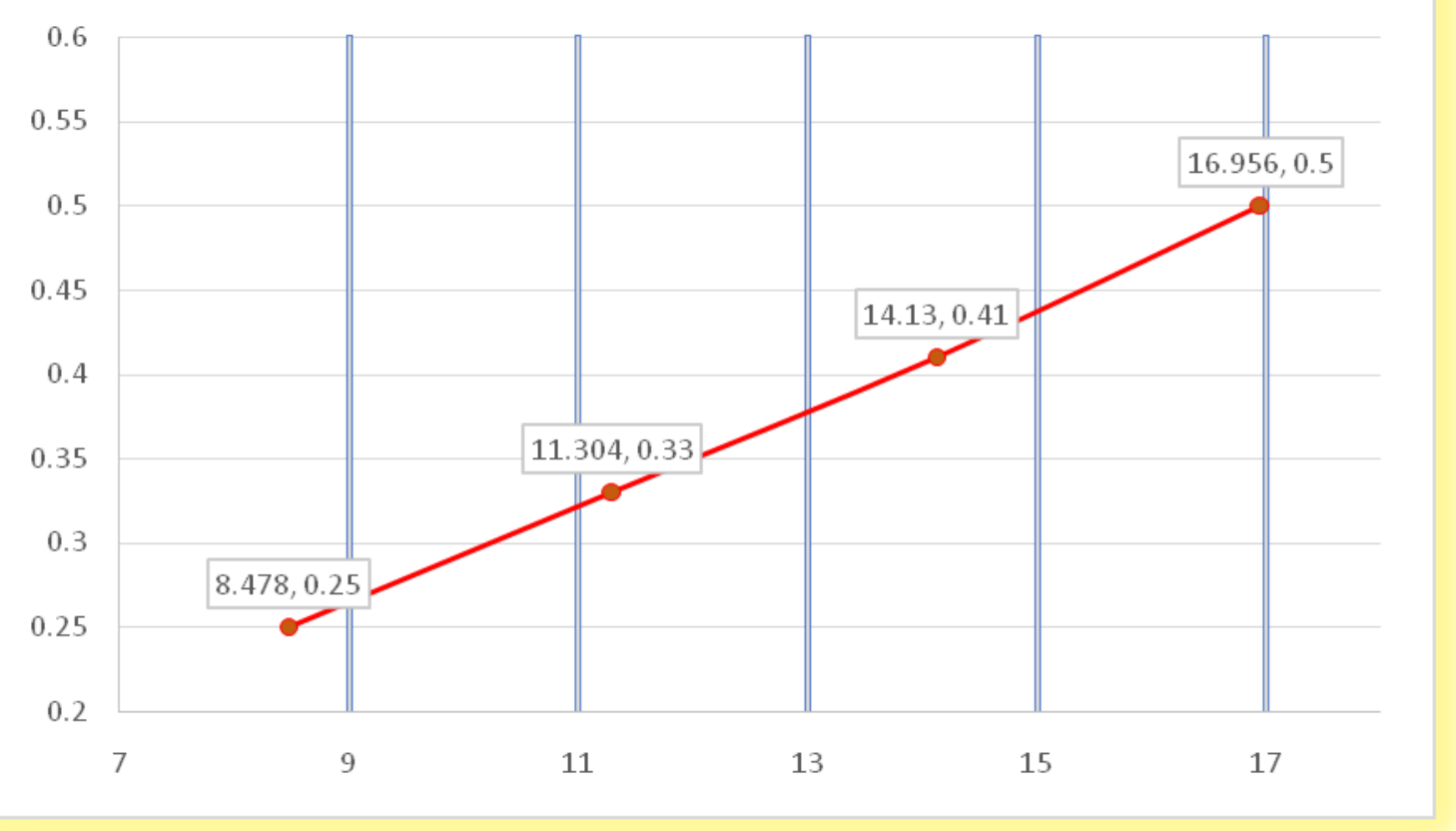

Fig.13 Graph for rotation per second of motor v/s Speed of the Robot 


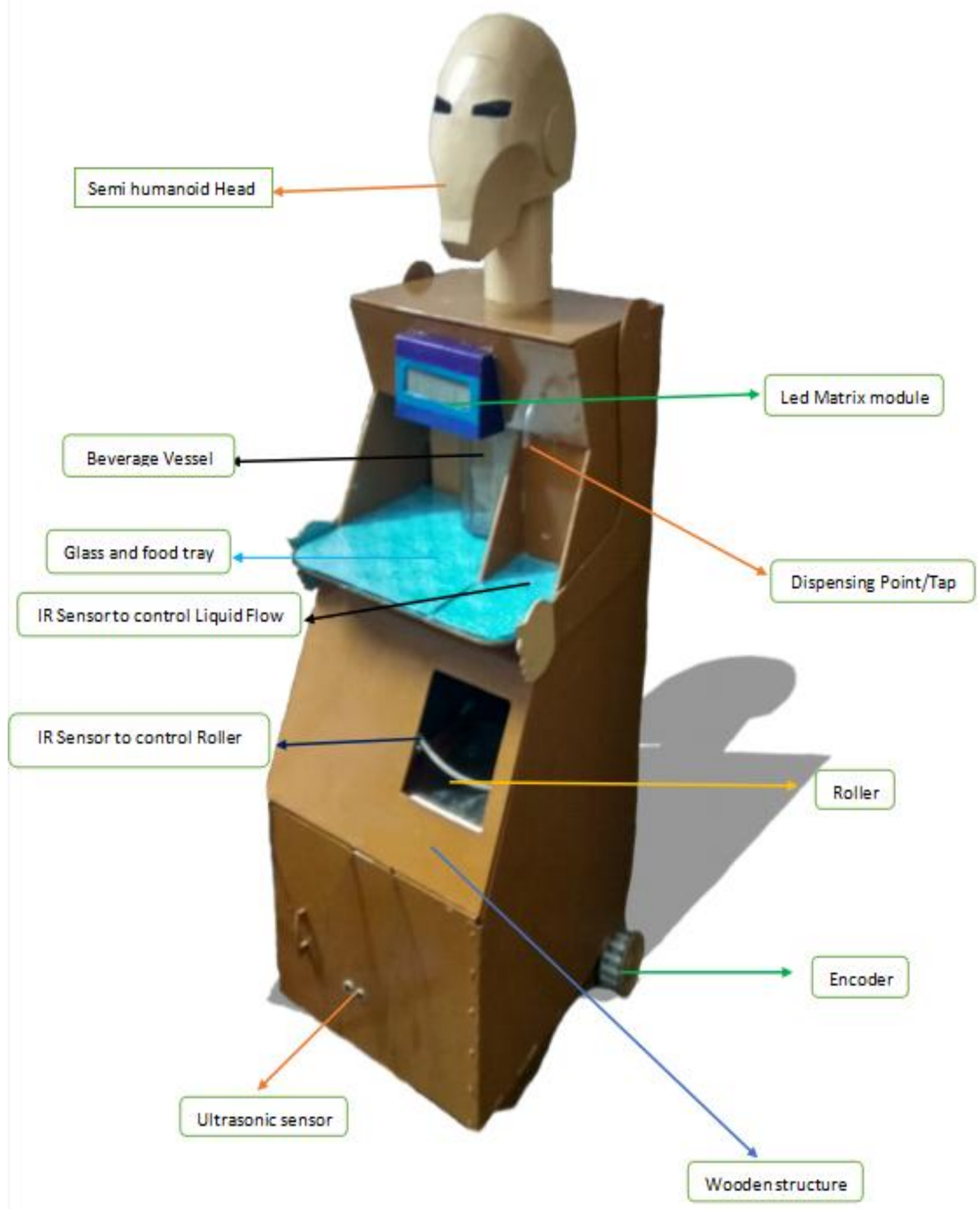

Fig.14 Serving robot with different fittings and attachments 
Above results were observed by taking storage container of 3 litre of beverage to fill the glasses although the quantity of storage container can be extended up to $10 \mathrm{~L}$. Time of 7.5 seconds was required to fill the glass of $250 \mathrm{ml}$ with the flow rate of $33.3 \mathrm{ml} / \mathrm{sec}$ which was controlled with the help of sensor timing. The quantity of supply can also be increased with the help of programming.

\section{Manual testing of robot}

In this testing the robot was totally controlled by remote app to made different turns, etc. It was controlled under human directions to make turns and reach the destination using the mobile-based Bluetooth app (Fig. 9).

\section{Automatic testing of robot}

In this testing, robot worked fully on its own after giving only one initial command, based on programmed path and worked without remote controlled system. In this process, only call me command was used to call the robot to perform the predefined task. The robot took automatic turns based on programed path and worked accordingly.

If there was any obstacle in the path, the robot would stop moving and the alarm would start ringing to provide information regarding the obstacle, which helps in preventing accidents. Fig. 14 shows the clear picture of this robot showing its different parts.

It worked very smoothly and took perfect turns as per RPM of wheels to reach the destination.

It can maintain good hygiene by avoiding human involvement in food \& beverage sectors and hospitals.

The sudden disturbance in the path of motion was sorted very well with the help of
Ultrasonic sensor resulting in decreasing the accidents risk.

The serving was done in both day and night times, because of lights fitted in the system, which also makes it attractive and visible.

Robot was found much accurate in terms of dispensing the predefined amount of beverage.

Bluetooth based mobile app which acted as a remote was found perfect upto a distance of $10 \mathrm{~m}$ and the remote commands were followed perfectly.

The battery backup was amazing as per no. of serving rounds, it can take more than 50 rounds on the basis of $35 \mathrm{~A}, 12 \mathrm{~V}$ battery and mentioned distance in table no.1.

The cost of manufacturing was cheaper according to the number of features it have. The total cost for the complete system was $15805 /-$ Rs.

\section{Future scope}

The developed robot can be scaled up with slighter modifications and can be used in highly labor-intensive processing industries for transportation purposes.

The battery used can be solar based, as there is a huge scope of sun's energy in a country like India where sun shines in abundance. Also there is a great need to shift towards renewable energy resources because of depleting conventional resources due to increased population and increased pollution (Sain 2019, Sain et al., 2019 a,b).

The Bluetooth range can be extended up to $100 \mathrm{~m}$ by changing the type of device used. 


\section{References}

Chivarov, S., Kopacek, P., \& Chivarov, N. 2019. Cost Oriented Humanoid Robot communication with IoT devices via MQTT and interaction with a Smart Home HUB connected devices. IFACPapersOnLine, 52(25), 104109. doi:10.1016/j.ifacol.2019.12.455

Hurd, S.A., Carnegie, D.A., Brown, N.R. and Gaynor, P.T. 2005. Development of an intelligent robotic system for the automation of a meat-processing task. Int J Intel Sys Technol Appl 1: 32-48

Khan, S.G., Herrmann, G., Al Grafi, M., Pipe, T., \& Melhuish, C. 2014. Compliance control and human-robot interaction: Part 1. Survey. International Journal of Humanoid Robotics , 11(3), 1430001. http://dx.doi.org/10.1142/S0219843614 300013

Narendra, V.G. and Hareesh, K.S. 2010. Quality inspection and grading of agricultural and food products by computer vision- A review. International Journal of Computer
Applications. 2:43-65

Nayik, G.A., Muzaffar, K. and Gull, A. 2015. Robotics and Food Technology. A Mini Review. J. Nutr. Food Sci.5: 384

Sain M. 2019. 'Study on development of solar energy based thermal reservoir for milk processing' M.tech Thesis, Guru Angad Dev Veterinary and Animal Sciences University, Ludhiana

Sain, M., Sharma, A., Talwar, G., and Goel N. 2019b. Thermic Fluid Based Solar Thermal Energy Storage System for Milk Processing. Int.J.Curr.Microbiol.App.Sci. 8(10):1962-1973.doi: https://doi.org/10.20546/ijcmas.2019.81 0.229

Sain, M., Sharma, A., Talwar, G., and Kumar, N. 2019a. Study on behaviour of thermal energy storage materials under conventional and solar heating systems. International Journal of Chemical Studies, 7(5): 732-738

Wallin, P.J., 1997. Robotics in the food industry, Trends in Food Science \& Technology. 8(5): 193-233.

\section{How to cite this article:}

Ramandeep Singh, Mukul Sain, Balveer Singh, Harpreet Singh Nagi and Niraj Bala. 2020. Development of a Cost Effective Beverage and Food-Serving Robot for Hygienically Outcomes and Human Comfort. Int.J.Curr.Microbiol.App.Sci. 9(05): 247-257. doi: https://doi.org/10.20546/ijcmas.2020.905.028 